\title{
Interfacial microstructure formation in A356/steel compound castings using metal coating
}

\author{
Aina Opsal Bakke ${ }^{1, *}$, Arne Nordmark ${ }^{2}$, Lars Arnberg ${ }^{1}$, and Yanjun $\mathrm{Li}^{1}$ \\ ${ }^{1}$ Norwegian University of Science and Technology, Trondheim, Norway \\ ${ }^{2}$ SINTEF Industry, Trondheim, Norway
}

\begin{abstract}
Compound castings between aluminum and steel have great potential for applications in the automotive industry. However, due to large differences in thermal and mechanical properties between steel and aluminum, and the formation of stable aluminum oxides at the interface, it is difficult to form high strength metallic bonding between the two metals. In this work, A356/steel compound castings were produced through a gravity casting process. Various metal coatings, including galvanizing, aluminizing and brass-coating, were applied on the steel inserts to ensure that the A356 aluminum melt could react sufficiently with an oxide-free steel surface, resulting in a high-quality metallurgical bond. The reaction layer formed between the alloys was investigated using Optical Microscopy (OM), Scanning Electron Microscopy (SEM) and Energy Dispersive X-ray Spectroscopy (EDS). In addition, Vickers Micro-hardness was measured across the aluminum-steel interface. Results showed that metallurgical bonding could be achieved with all three coatings. However, for the brass-coated components only local bonding areas were found. In the aluminized and galvanized components, thick reaction layers consisting of binary $\mathrm{Al}-\mathrm{Fe}$ and ternary $\mathrm{Al}-\mathrm{Fe}-\mathrm{Si}$ phases formed in the aluminum-steel interface. Between the A356 aluminum and aluminized layer, nearly no reaction layer formed. The mechanism for the formation of the various intermetallic phases at the reaction layers are discussed.
\end{abstract}

\section{Introduction}

Aluminum alloy A356 is widely used in automotive castings due to its great castability, corrosion resistance and strength-to-weight ratio, especially in the heat-treated condition $[1,2]$. However, steel is still superior in terms of strength which makes it difficult to completely replace steel with aluminum alloys. Therefore, the need for a multi-material solution, such as an aluminum-steel compound, arises. To achieve specific property- and functional requirements, new methods must be developed to joint aluminum and steel effectively.

Compound casting is a casting process where two materials, one in solid state and one in liquid state, are joined together. In the process, the liquid material is cast around the solid, thus forming a diffusion zone between the two metals, which results in a metallurgical bond. This joining process is considered economically favorable in largescale production, due to reduction of process steps [3].

A challenge in compound casting is that a range of brittle Al-Fe intermetallic phases form at the interface, which is detrimental to the overall bonding strength [4]. Compound casting is also difficult due to aluminum oxides forming spontaneously on the metal surface [5]. These oxides are very stable and have high melting points [6]. Therefore, it is difficult to achieve desired wettability between aluminum and steel, which will hinder formation of a metallurgical bond.

*e-mail: aina.o.bakke@ntnu.no
Numerous approaches have been considered in order to achieve metallurgical bonding between aluminum and steel. The most common method is to apply a thin coating layer on the steel surface, such as flux coating or coating with a low melting point metal. Zinc coating has been reported to improve bonding, as it prevents the steel from oxidizing and has a lower melting point than aluminum [6]. This allows the zinc coating to melt during casting, leaving a clean steel surface for the aluminum to react.

Springer, Szczepaniak and Raabe tested both hotdipped $\mathrm{Zn}$ coating and electrolytic-coated $\mathrm{Zn}$ on lowcarbon steel in a dip-test experiment in liquid Al. They found that $\mathrm{Zn}$-coating accelerated the growth of intermetallic phases as well as formation of a more uniform reaction layer. A hot-dip $\mathrm{Zn}$ layer appeared to have the largest effect on the results [7]. Kang and Kim joined Al5052 and aluminized steel through an arc braze welding process. The aluminized layer was approximately 30 $\mu \mathrm{m}$ thick and consisted of an AlSi layer and an $\mathrm{Fe}_{x}(\mathrm{AlSi})_{y}$ layer, where the latter formed during the aluminizing process. It showed that although the aluminized steel showed slightly lower wettability compared to a galvanized steel sample, the layer of intermetallic phases was thinner for the aluminized joints [8].

The influence of various surface treatments of steel inserts in a compound casting process with aluminum alloy ZL114A, has been studied by Jiang et al. [9]. The hot-dip aluminized layer was found to improve the bonding compared to the uncoated steel. By using $\mathrm{NH} 4 \mathrm{Cl}$ as 
a surface modifier prior to aluminizing, a reaction layer formed in the interface causing the formation of a metallurgical bond, which significantly improved the overall bonding. Hot-dip galvanizing of cylindrical steel inserts in a $\mathrm{Zn}$ melt with $0.1 \mathrm{wt} \% \mathrm{Ni}$ improved wettability between the steel and the ZL114A aluminum melt. Although this helped formation of a metallurgical bond, it resulted in a relatively thick reaction layer ( $\sim 650 \mu \mathrm{m}$ thickness) [10]. Combining galvanizing and aluminizing also showed improved bonding compared to joining aluminum ZL114A to a bare grey iron surface. Galvanizing followed by aluminizing caused the aluminized layer to form a reaction layer with the grey iron due to enhanced wettability. This reaction layer then reacted further with the cast aluminum alloy, resulting in a near uniform reaction layer in the final component [11].

In the present research, the interface structure and bonding properties between S235JR steel pipes, coated with three different metallic coating layers, and aluminum alloy A356 were investigated. The different coatings were: galvanizing, aluminizing and brass-coating. Aluminumsteel compound castings were produced in a sand mold through a gravity casting process. Resulting microstructure in the interface was investigated. In addition, Vickers microhardness was measured across the interface of the various castings in order to assess the overall bonding properties of the castings.

\section{Experimental Procedure}

Compound castings between aluminum and steel were produced through a gravity casting process using a sand mold, shown in Figure 1. S235JR steel pipes with an outer diameter of $20 \mathrm{~mm}$, a wall thickness of $1.5 \mathrm{~mm}$ and a length of $155 \mathrm{~mm}$, were used as inserts in the sand mold. Aluminum alloy A356 was used as the casting alloy. Compositions of both materials are given in Table 1 .

\subsection{Surface Treatments}

Three different surface coatings were tested in the experiment. One third of the steel pipes were galvanized through an industrial hot-dipping process. The steel pipes were immersed into the $\mathrm{Zn}$ bath in a centrifuge to ensure uniform coating. One third of the steel pipes were brass-coated. The coating was performed by dipping the steel pipes in a cartridge brass (C260) bath at approximately $1200^{\circ} \mathrm{C}$. Boric acid is added to the bath to ensure better wetting and prevent oxide formation during coating. The remaining steel pipes were aluminized. First, they were ground with 1200 grit paper, cleaned in ethanol and then immersed in a $10 \% \mathrm{NH}_{4} \mathrm{Cl}$ solution for five minutes at $75^{\circ} \mathrm{C}$ followed by air-drying. The salt-coated steel pipes were then preheated to $150^{\circ} \mathrm{C}$ and then dipped in a liquid aluminum AlSi7 melt at $800^{\circ} \mathrm{C}$ for five minutes.

\subsection{Material Characterization}

Samples with a thickness of $1 \mathrm{~cm}$ were cut from each casting perpendicular to the aluminum/steel interface. Following cutting, the samples were ground to 4000 grits on

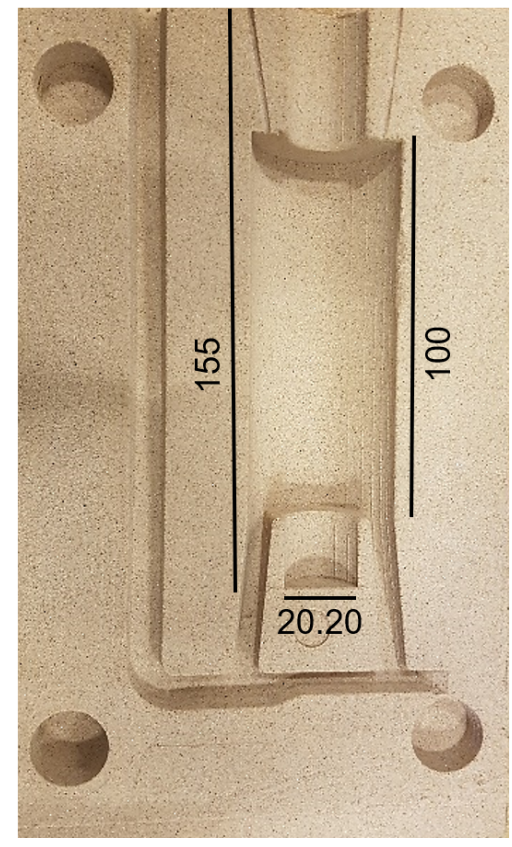

Figure 1: Sand mold used in the casting experiments. All dimensions are given in millimeters.

a Struers LaboPol-21 grinding machine and subsequently polished with $3 \mu \mathrm{m}$ and $1 \mu \mathrm{m}$ diamond suspension on a Struers Tegramin-20 polishing machine. To examine the bonding properties and microstructures at the interface, a Zeiss Supra 55VP Field Emission Scanning Electron Microscope (FESEM) with Energy Dispersive X-ray Spectroscopy (EDS) was used. The FESEM was operated with a $10 \mathrm{~mm}$ working distance and $15 \mathrm{kV}$ acceleration voltage.

\section{Results}

\subsection{Influence of galvanized coating}

In Figure 2a, a macroscopic image of the compound casting sample where a galvanized steel pipe was used. On one side of the interface a large cavity has formed, whereas the remaining interface appears to show good bonding between the steel pipe and cast aluminum. Figure $2 b$ shows an optical micrograph of the aluminum-steel interface in the same casting sample. The irregular steel surface, along with a thin layer at the surface that appears to be slightly darker, suggests formation of intermetallic phases. Within certain areas large intermetallic particles are seen growing from the thin layer towards the cast aluminum. In addition, some platelet shaped particles can be observed in the cast aluminum adjacent to the interface. As these particles are regarded as part of the reaction layer, it shows that there is a slight variation in the reaction layer thickness.

The platelet particles can be better observed in the backscattered SEM images in Figure 3. The contrast clearly shows that intermetallic particles are growing from the steel surface towards the cast aluminum. In this area of the casting, the reaction layer at the interface has a thickness varying from $20-50 \mu \mathrm{m}$, whereas platelet particles can 
Table 1: Chemical composition in wt.\% of S235JR steel and A356 aluminum.

\begin{tabular}{cccccccccc}
\hline & $\mathrm{Mn}$ & $\mathrm{C}$ & $\mathrm{P}$ & $\mathrm{S}$ & $\mathrm{Fe}$ & & & & \\
S235JR [12] & 1.4 & 0.17 & 0.045 & 0.045 & $\mathrm{Bal}$. & & & & \\
\hline & $\mathrm{Si}$ & $\mathrm{Mg}$ & $\mathrm{Ti}$ & $\mathrm{Fe}$ & $\mathrm{Sr}$ & $\mathrm{Ga}$ & $\mathrm{Zn}$ & Others & $\mathrm{Al}$ \\
A356.0 & 7.03 & 0.4052 & 0.1076 & 0.0822 & 0.0131 & 0.0089 & 0.0042 & 0.0029 & Bal. \\
\hline
\end{tabular}

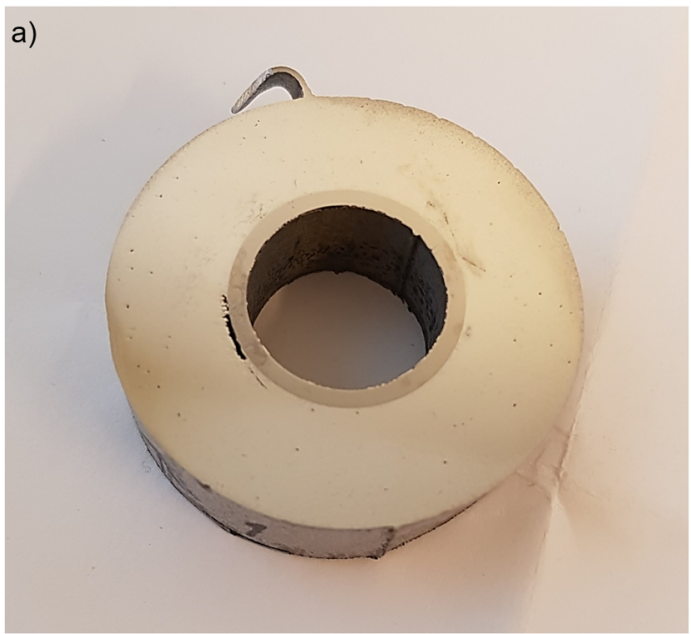

(a) Image of a casting sample with a galvanized steel pipe. A cavity can be observed on one side of the aluminum-steel interface.

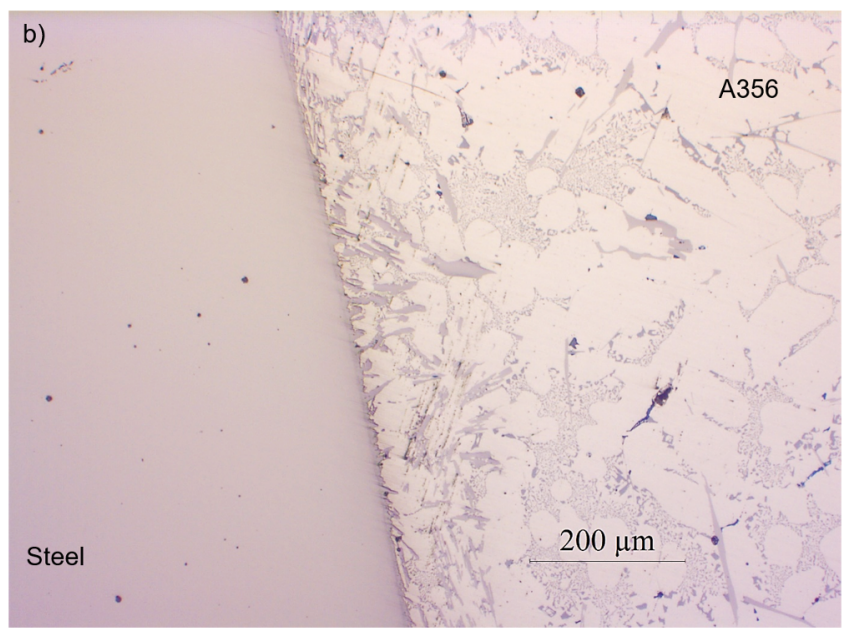

(b) Optical micrograph of the aluminum-steel interface in the galvanized casting. Intermetallic particles with platelet shape can be seen in the interface

Figure 2: Macro- and microscopic images of the compound casting with a galvanized steel insert.
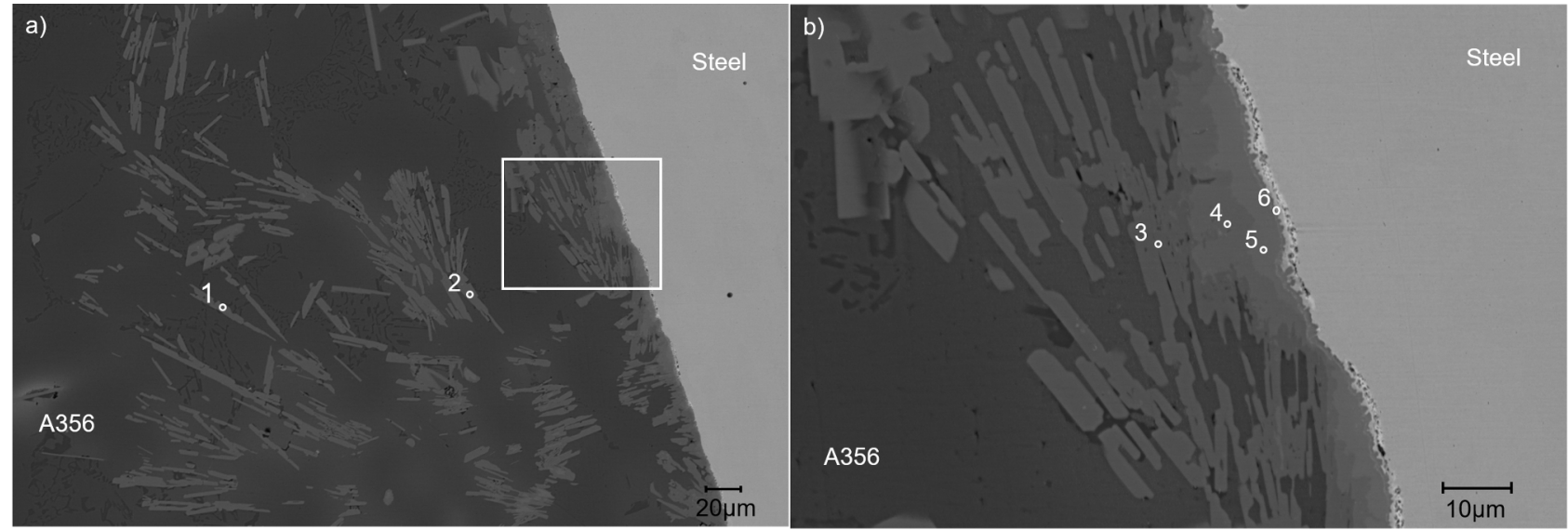

Figure 3: Backscattered micrograph showing the intermetallic phases formed at the aluminum-steel interface in the galvanized casting. b) shows the area marked with a white rectangle in a). Marked areas were analyzed by EDS.

be observed up to $300 \mu \mathrm{m}$ from the interface. The intermetallic particles framed by the white rectangle in Figure 3a were further investigated at a higher magnification. As seen in Figure $3 b$, there is a slight contrast difference in the intermetallic layer growing at the steel surface. This suggests that multiple phases have formed in the reaction layer, as confirmed by the EDS analysis shown in Table 2.

From Table 2 it can be seen that the platelet-shaped particles formed outside the interface are the ternary eu- tectic phase, $\mathrm{Al}_{4.5} \mathrm{FeSi}$. Due to the sharp edges, such particles can be areas of stress initiation and would therefore decrease the overall bonding strength [13]. Similar platelet particles were observed at the aluminum-steel interface and was again determined to be $\beta-\mathrm{Al}_{4.5} \mathrm{FeSi}$, as seen in Area 3 in Table 2. In addition, two other phases were found to form between $\beta$ - $\mathrm{Al}_{4.5} \mathrm{FeSi}$ and the steel pipe, as can be observed by the slight contrast variation in Figure 3b. The compositions suggest formation of $\alpha-\mathrm{Al}_{7.4} \mathrm{Fe}_{2} \mathrm{Si}$ 
Table 2: Chemical composition detected through EDS analysis and possible formed phases in the marked areas in Figure 3.

\begin{tabular}{cccccc}
\hline Area & \multicolumn{4}{c}{ Composition [at\%] } & Possible Phase \\
& $\mathrm{Al}$ & $\mathrm{Si}$ & $\mathrm{Fe}$ & $\mathrm{Zn}$ & \\
\hline 1 & 67.19 & 16.95 & 14.99 & 0.87 & $\beta-\mathrm{Al}_{4.5} \mathrm{FeSi}$ \\
2 & 67.76 & 16.87 & 15.38 & - & $\beta-\mathrm{Al}_{4.5} \mathrm{FeSi}$ \\
3 & 67.08 & 16.03 & 15.13 & 1.76 & $\beta-\mathrm{Al}_{4.5} \mathrm{FeSi}$ \\
4 & 69.40 & 9.94 & 19.89 & 0.77 & $\alpha-\mathrm{Al}_{7.4} \mathrm{Fe}{ }_{2} \mathrm{Si}$ \\
5 & 72.69 & 2.97 & 23.49 & 0.85 & $\mathrm{Al}_{3} \mathrm{Fe}$ \\
6 & 63.43 & 3.62 & 30.63 & 2.31 & $\mathrm{Al}_{5} \mathrm{Fe}_{2}$ or $\mathrm{Al}_{2} \mathrm{Fe}$ \\
\hline
\end{tabular}

and $\mathrm{Al}_{3} \mathrm{Fe}$ with the latter closest to the steel pipe. At the immediate steel surface, there is an area with a layer of brighter contrast. The increased $\mathrm{Zn}$ concentration in Area 6 suggests that this bright layer is a Zn-enriched layer, showing that some of the galvanized layer remained at the interface. In this area, a higher concentration of $\mathrm{Fe}$ was detected, with the aluminum-iron ratio suggesting formation of $\mathrm{Al}_{2} \mathrm{Fe}$. However, as $\mathrm{Al}_{2} \mathrm{Fe}$ and $\mathrm{Al}_{5} \mathrm{Fe}_{2}$ have similar compositions and $\mathrm{Al}_{5} \mathrm{Fe}_{2}$ often has been reported as the dominating phase forming in the Al-Fe system, it is possible that $\mathrm{Al}_{5} \mathrm{Fe}_{2}$ has formed adjacent to the steel surface [14]. This shows that the iron concentration increases in the intermetallic phases towards the steel pipe, which coincides with higher iron diffusion at the steel surface. All phases detected in the reaction layer are known phases in the ternary Al-Fe-Si and binary Al-Fe systems [15]. It should also be noted that zinc is barely detected in any of the analyzed areas, showing that upon re-melting of the galvanized layer, zinc has dissolved in the aluminum.

\subsection{Influence of aluminized coating}

For the compound castings with aluminized steel inserts, no defects could be observed in the aluminum-steel interface macroscopically (Figure 4a), suggesting metallurgical bonding. However, microscopic investigations revealed that the aluminized layer remained in the interface throughout the casting. This can be seen in Figure $4 \mathrm{~b}$, where the aluminized layer has a different color compared to the cast aluminum. Good bonding between the cast aluminum and the aluminized layer appears to have formed. The aluminized layer has a relatively uniform thickness of approximately $60 \mu \mathrm{m}$. Also observed in the aluminized casting, is the tongue-like intermetallic particles growing from the aluminized layer into the bulk of the steel pipe. Such microstructures are known to form in aluminized steels [16]. This differs from the compound castings with galvanized steel, where the intermetallic phases grew into the cast aluminum.

Figure 5 shows two BSE images of different areas of the reaction layer formed between aluminum and aluminized steel. The interface between the aluminized layer and the cast aluminum can be clearly seen. In Figure $5 \mathrm{a}$ the interface can be seen based on the difference in eutectic structure. Bright long platelet-shaped particles are laying along the interface in Figure 5a (Area 1). In Figure 5b, there is a gap between the cast aluminum and aluminized layer, showing that no metallurgical bonding formed in this area. Additionally, a large amount of bright long particles have formed in the aluminized layer.

Table 3: Composition and possible phases formed in the reaction layer of an aluminized casting. Areas coincide with the shown areas in Figure 5.

\begin{tabular}{|c|c|c|c|c|}
\hline \multirow[t]{2}{*}{ Area } & \multicolumn{3}{|c|}{ Composition [at\%] } & \multirow[t]{2}{*}{ Possible Phase } \\
\hline & $\mathrm{Al}$ & $\mathrm{Si}$ & $\mathrm{Fe}$ & \\
\hline 1 & 69.07 & 16.63 & 14.30 & $\beta-\mathrm{Al}_{4.5} \mathrm{FeSi}$ \\
\hline 2 & 75.31 & 0.75 & 23.94 & $\mathrm{Al}_{3} \mathrm{Fe}$ \\
\hline 3 & 72.36 & - & 27.64 & $\mathrm{Al}_{5} \mathrm{Fe}_{2}$ \\
\hline 4 & 85.99 & - & 14.01 & $\mathrm{Al}_{3} \mathrm{Fe}$ \\
\hline 5 & 90.51 & - & 9.49 & $\mathrm{Al}_{3} \mathrm{Fe}$ \\
\hline 6 & 76.55 & - & 23.45 & $\mathrm{Al}_{3} \mathrm{Fe}$ \\
\hline
\end{tabular}

From Table 3, it appears that the particles observed in the boundary between the aluminized layer and the cast aluminum are ternary $\mathrm{Al}_{4.5} \mathrm{FeSi}$ (Area 1 in Figure 5a). The particles appear to have a platelet shape, which coincides with the platelet structure observed for the castings with galvanized steel in Figure 3. However, as they are placed between the cast aluminum and the aluminized layer, their placement is likely detrimental to the bonding strength. The intermetallic particles in Area 2 and 3 in Figure 5a appear to be the binary phases $\mathrm{Al}_{3} \mathrm{Fe}$ and $\mathrm{Al}_{5} \mathrm{Fe}_{2}$, although their chemical composition is very similar. $\mathrm{Al}_{5} \mathrm{Fe}_{2}$ can be recognized by its characteristic tongue-like morphology as it grows towards the steel pipe [15]. As the aluminized layer can still be observed in the interface, it is assumed that the binary Al-Fe phases formed during the aluminizing process. Nonetheless, bonding was observed locally in multiple areas.

In the aluminized area shown in Figure $5 \mathrm{~b}$, the particles appear to be binary Al-Fe particles. The compositions detected through EDS (Area 4 and 6 in Table 3) do not coincide with any known $\mathrm{Al}-\mathrm{Fe}$ phase, but as the particles are very thin it is likely that some of the surrounding $\mathrm{Al}$ matrix has been detected in the analysis. The intermetallic tongue-like reaction layer has a slightly different contrast at the interface with the aluminized layer compared to the outer particles. This can also be observed in 5a. Area 2 and Area 6 have similar compositions, suggesting that the same phase has formed in both areas, likely $\mathrm{Al}_{3} \mathrm{Fe}$. Therefore, it is possible that the binary particles formed in the aluminized layer in Figure $5 \mathrm{~b}$ are also $\mathrm{Al}_{3} \mathrm{Fe}$.

\subsection{Influence of brass-coating}

Figure 6 shows an image of a casting sample with a brasscoated steel insert. Multiple small cavities can be seen throughout the aluminum-steel interface, suggesting poor bonding.

Further investigation of the compound castings with brass-coated steel showed that the brass layer remained on the steel surface in most areas. Figure 7 shows two BSE 


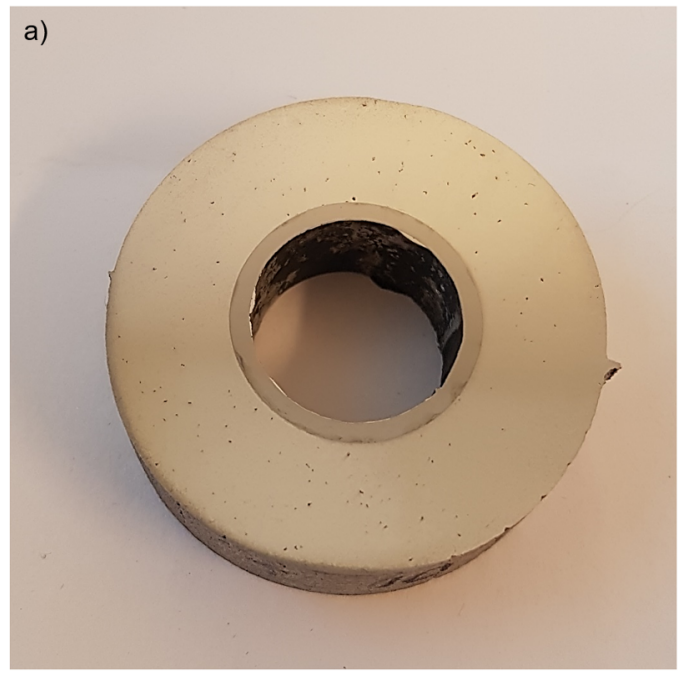

(a) Image of a casting sample with an aluminized steel pipe. No visible defects can be observed in the aluminum-steel interface.

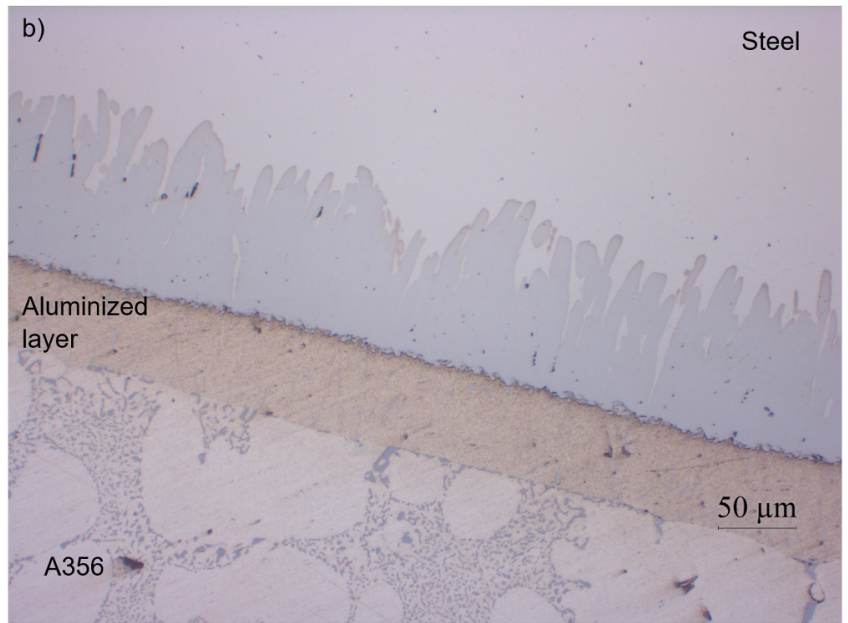

(b) Optical micrograph of the interface in the aluminized casting. An intermetallic phase can be seen growing towards the steel pipe, and the aluminized layer is still intact after casting.

Figure 4: Macro- and microscopic images of the compound casting with an aluminized steel insert.
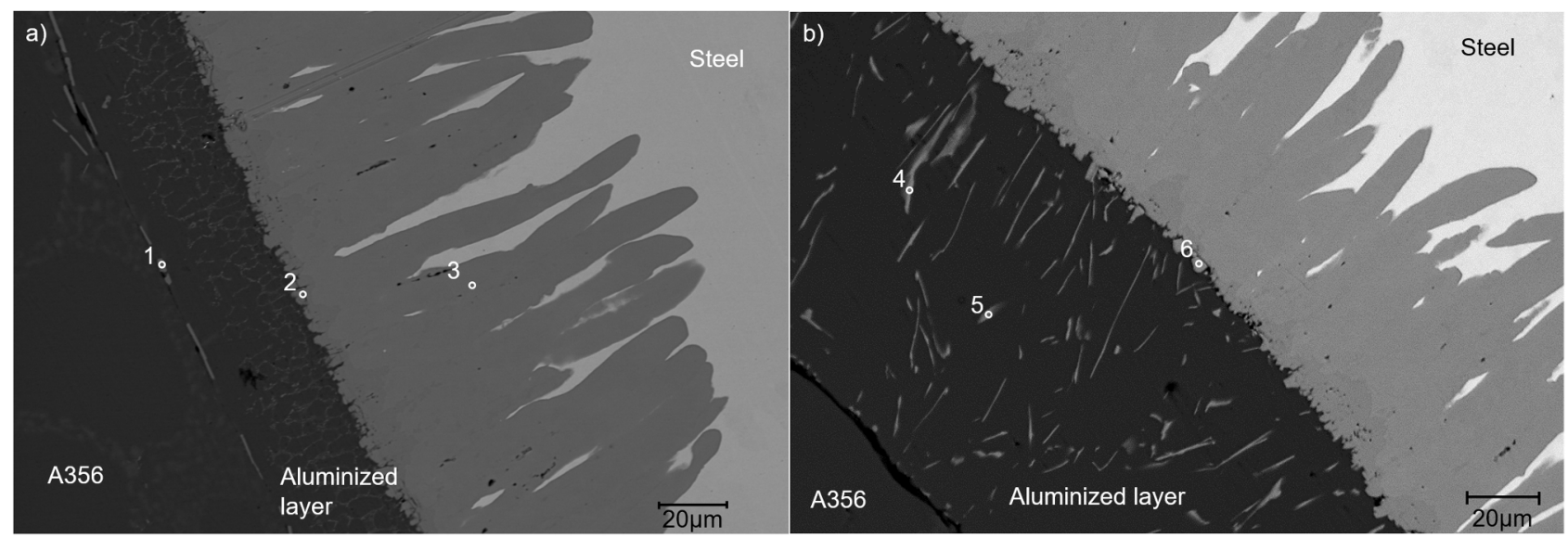

Figure 5: Micrographs of the reaction layer in two different areas in the aluminum-steel interface of an aluminized casting. Marked areas were analysed through EDS.

SEM images of different areas of the aluminum-steel interface. In Figure 7a, most of the brass layer remained on the steel surface, and no metallurgical bonding between this layer and the cast aluminum can be observed. Figure $7 \mathrm{~b}$, however, shows an area where a reaction layer has formed. However, several cracks and gaps can be observed on the cast aluminum side outside the reaction layer, indicating that no continuous bond has formed despite the reaction layer.

Although most of the brass layer remain unchanged on the steel surface, small local areas that reacted with the cast aluminum could be found (Areas 2, 3 and 4 in Figure 7a). The reaction area has a droplet-like shape, where the contrast in the figure suggests that multiple phases have formed. From the EDS analysis in Table 4, these phases were determined to be $\mathrm{Al}_{2} \mathrm{Cu}_{3}, \mathrm{AlCu}$ and a quater- nary phase $\mathrm{Al}_{5} \mathrm{Cu}_{2} \mathrm{Mg}_{8} \mathrm{Si}_{6}$, which is frequently observed in $\mathrm{Al}-\mathrm{Si}-\mathrm{Cu}-\mathrm{Mg}$ alloys with high $\mathrm{Cu} / \mathrm{Mg}$ ratio [17]. The binary $\mathrm{Al}-\mathrm{Cu}$ phases are suggested to form through solid state phase transformation from the eutectic $\mathrm{Al}_{2} \mathrm{Cu}$ phase [18]. As the reaction area is relatively small, it is believed that some local melting of the brass layer has occurred due to local differences in temperature at the interface.

EDS analysis from the reaction layer shown in Figure $7 \mathrm{~b}$ shows that ternary Al-Fe-Si phases have formed. The intermetallic phase adjacent to the steel surface with a slightly brighter contrast (Area 6 in Table 4) has a composition close to the $\alpha-\mathrm{Al}_{7.4} \mathrm{Fe}_{2} \mathrm{Si}$ phase. The composition of the intermetallic particles close to the cast aluminum side is close to the ternary eutectic phase $\beta-\mathrm{Al}_{4.5} \mathrm{FeSi}$. Interestingly, most of the areas analyzed showed low concentrations of copper, while no zinc was detected. This suggests 
Table 4: Composition and possible phases formed in the reaction layer of a brass-coated casting. Areas coincide with the shown areas in Figure 7.

\begin{tabular}{ccccccccc}
\hline Area & \multicolumn{9}{c}{ Composition [at\%] } \\
& $\mathrm{Al}$ & $\mathrm{Si}$ & $\mathrm{Fe}$ & $\mathrm{O}$ & $\mathrm{Cu}$ & $\mathrm{Zn}$ & $\mathrm{Mg}$ & \\
\hline 1 & 1.38 & - & 3.34 & 2.96 & 69.88 & 22.45 & - & Cartridge brass \\
2 & 33.31 & - & 3.26 & 2.25 & 54.14 & 7.04 & - & $\mathrm{Al} 2 \mathrm{Cu} 3$ \\
3 & 37.55 & - & 2.52 & 2.69 & 44.15 & 13.09 & - & $\mathrm{AlCu}$ \\
4 & 23.11 & 27.87 & - & 0.34 & 12.75 & - & 35.94 & $\mathrm{Al}$ Cu2Mg8Si6 \\
5 & 67.90 & 15.88 & 15.44 & - & 0.78 & - & - & Al4.5FeSi \\
6 & 67.41 & 10.14 & 17.83 & - & 4.63 & - & - & Al7.4Fe2Si \\
\hline
\end{tabular}

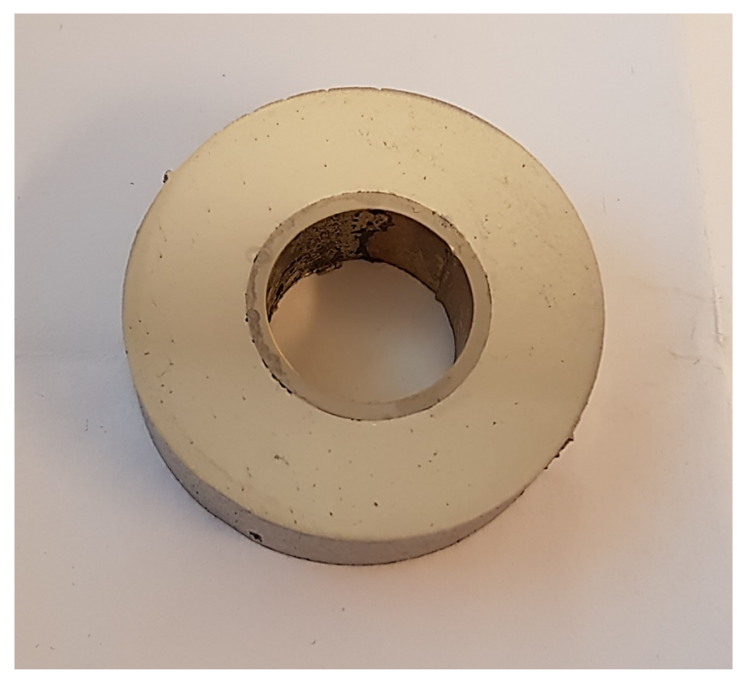

Figure 6: Image of a casting sample with a brass-coated steel pipe. Small cavities can be observed throughout the aluminum-steel interface.

that both copper and zinc have dissolved and diffused into the cast aluminum upon re-melting during casting.

\subsection{Vickers microhardness}

Vickers micro-hardness was measured across the reaction layer in each casting. The hardness profiles are plotted in Figure 8a for comparison. Microhardness indentations for the aluminum-steel interfaces in the galvanized, aluminized and brass-coated castings are shown in Figures $8 \mathrm{~b}, 8 \mathrm{c}$ and $8 \mathrm{~d}$, respectively. Origin in the figure is set at the interface between the steel pipe and the cast aluminum in the galvanized and brass-coated castings, and the cast aluminum and the aluminized layer in the aluminized casting.

From the graph, it is clear to see that the intermetallic Al-Fe and Al-Fe-Si phases forming at the reaction layer, have much higher hardness than the steel pipe and cast aluminum. For the aluminized castings, the hardness increases gradually from the steel pipe towards the aluminized layer due to the formation of $\mathrm{Al}_{5} \mathrm{Fe}_{2}$ and $\mathrm{Al}_{3} \mathrm{Fe}$. The gradual increase is likely due to the tongue-like morphology causing an increased area of $\mathrm{Al}_{5} \mathrm{Fe}_{2}$ towards the aluminized layer. In addition, the hardness reaches a peak close to the aluminized layer, suggesting that $\mathrm{Al}_{3} \mathrm{Fe}$ is harder than $\mathrm{Al}_{5} \mathrm{Fe}_{2}$. The reaction layer in the galvanized castings also show higher hardness than the steel pipe and cast aluminum, however not to the same extent as the aluminized castings. The hardness peak in the cast aluminum of the galvanized casting is due to the indentation being at an area of intermetallic particles outside the reaction layer at the steel surface. For the brass-coated castings, no hardness peaks were observed. This suggests that the remaining brass layer has a hardness between those of A356 and steel.

\section{Discussion}

In all three compound castings, binary Al-Fe or ternary Al$\mathrm{Fe}-\mathrm{Si}$ phases have formed in the reaction layers. By comparing the three surface treatments, it can be concluded that a more continuous metallurgical bond can be achieved by using galvanized steel inserts, deeming this the best surface treatment out of the three. However, it should be noted that in the castings with galvanized steel inserts, large Al-Fe-Si intermetallic particles are also found in the bulk of the cast aluminium with some distance to the continuous reaction layer at the interface. These particles are likely formed as a result of the galvanized layer remelting upon casting. During the galvanization process, diffusion of iron and zinc atoms lead to the formation of several FeZn phases in the final galvanized layer. Usually the first phases to form during this process are the binary phases $\mathrm{FeZn}_{10}$ and $\mathrm{FeZn}_{13}$ [19]. The temperature of the liquid A356 is above the peritectic temperatures for both these phases through the reactions $\mathrm{L}+\Gamma-\mathrm{Fe}_{3} \mathrm{Zn}_{10} \leftrightarrow \delta-\mathrm{FeZn} \mathrm{n}_{10}$ at $672^{\circ} \mathrm{C}$ and $\mathrm{L}+\delta-\mathrm{FeZn}_{10} \leftrightarrow \zeta-\mathrm{FeZn}_{13}$ at $530^{\circ} \mathrm{C}[20,21]$. This allows for remelting during casting and thus leave excessive iron atoms in the melt. Therefore, iron atoms diffuse from the steel surface into the aluminum melt and ternary eutectic $\beta$ - $\mathrm{Al}_{4.5} \mathrm{FeSi}$ particles can form in the cast A356. This phase is known for its characteristic platelet morphology, which can be detrimental to bonding strength as the sharp edges can induce stress concentrations and therefore fracture can propagate along the interface of the particle-aluminum matrix interface [13]. In addition, the size of the $\beta-\mathrm{Al}_{4.5} \mathrm{FeSi}$ particles are important for the overall strength of the casting. It was reported by Ma et al. that there is a significant decrease in the ultimate tensile strength and elongation when the particle length increases to approximately $70 \mu \mathrm{m}$ [22]. Such particles were also ob- 


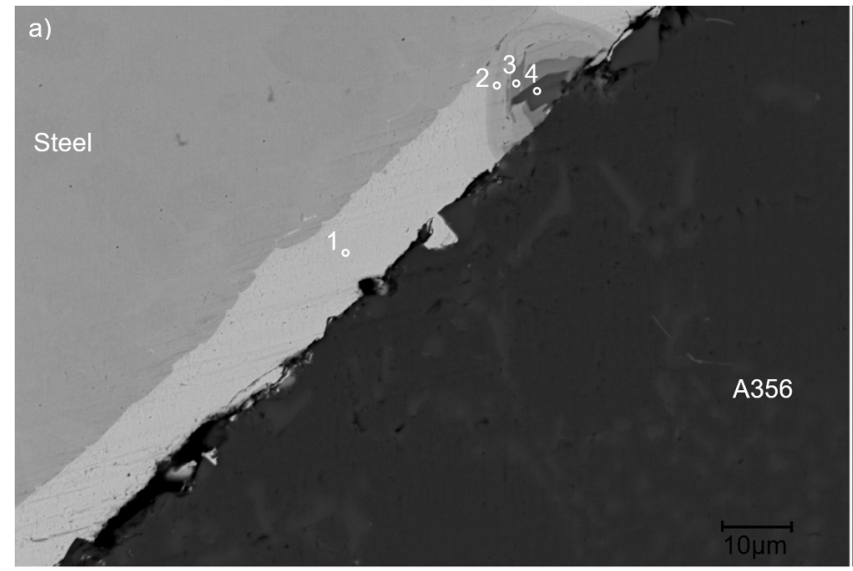

(a) Area where the brass-layer remained at the steel surface.

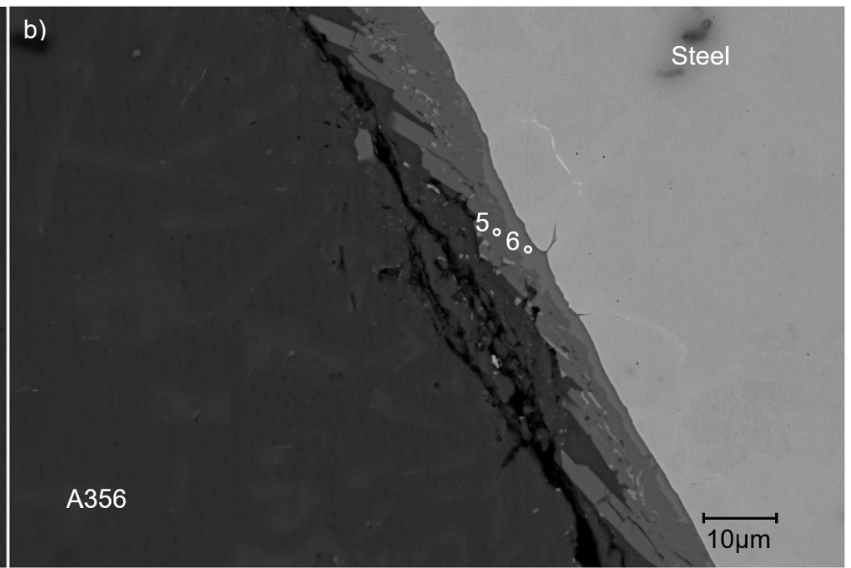

(b) Area of a reaction layer in the aluminum-steel interface.

Figure 7: BSE micrographs of the aluminum-steel interface in a brass-coated casting. The marked areas were analyzed through EDS.

a)

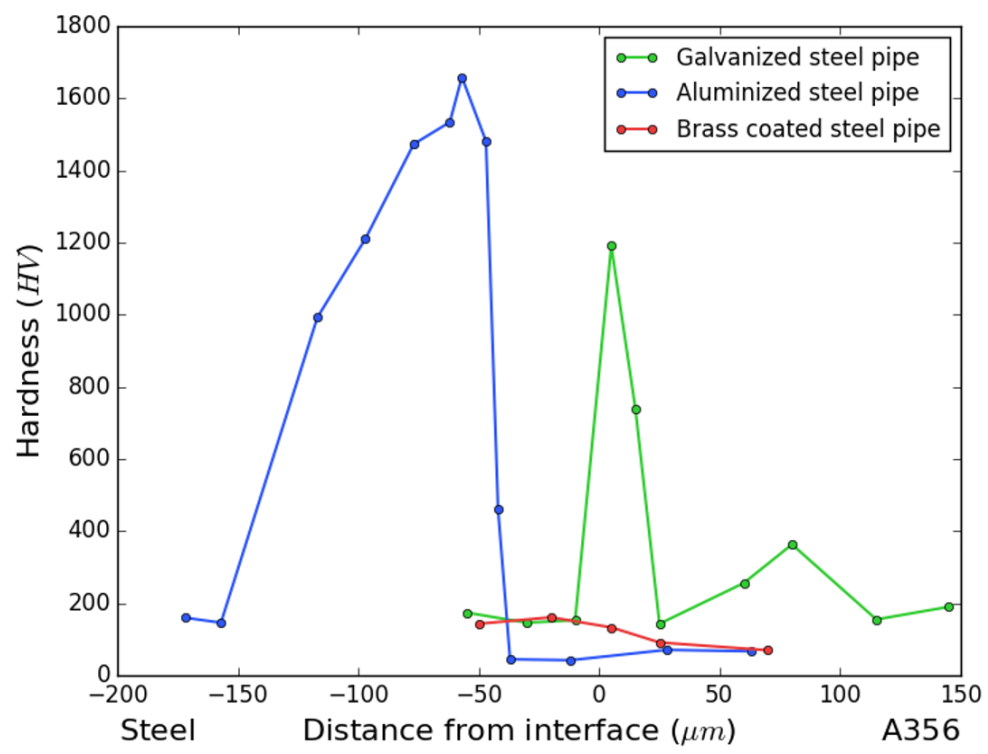

(a)

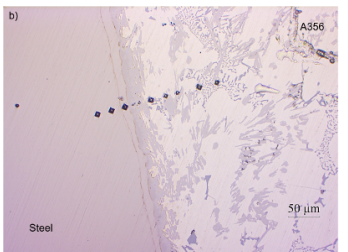

(b)

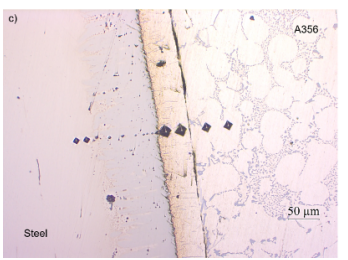

(c)

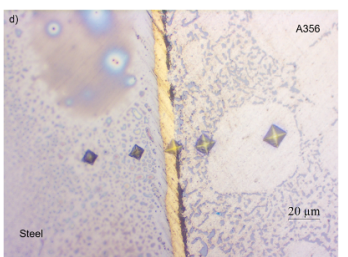

(d)

Figure 8: Micro-hardness measured across the reaction layer for the castings with various surface treatment. Origin is set at the interface between the steel pipe and the cast aluminum in the galvanized and brass-coated castings, and the cast aluminum and the aluminized layer in the aluminized casting.

served at the interface between the A356 aluminum and aluminized layer on the steel inserts. As the aluminized layer did not remelt during casting, less Fe will be available. The number of $\beta-\mathrm{Al}_{4.5} \mathrm{FeSi}$ particles is therefore much less in this casting, with the size also being significantly smaller. However, as these particles appear to have formed along the interface between the cast A356 and the A356 from the aluminizing process, it is likely to reduce strength of the overall bond and that fracture can easily occur in this interface.

The eutectic point in the binary $\mathrm{Al}-\mathrm{Cu}$ system is at 17 at $\% \mathrm{Cu}$ and $550^{\circ} \mathrm{C}$ [23], whereas in the Al-Zn system the eutectic point is at 88.7 at $\% \mathrm{Zn}$ and $381^{\circ} \mathrm{C}$ [24]. This means that in principle the brass coating-layer could remelt and react with the liquid cast aluminum. However, for the castings with brass-coated steel inserts, the coating- 
layer remained intact in most areas. This is likely due to the oxide layers forming on the liquid aluminum and brass surfaces. Qiu and Legraf tested the oxidation of commercial brass sheets (20 wt.\% Zn) in humidified air and found that a two-phase oxide layer consisting of large areas enriched with $\mathrm{Cu}_{2} \mathrm{O}$ with smaller areas of $\mathrm{ZnO}$ in between [25]. Such passive oxide layers significantly reduce wettability and reaction with the liquid cast A356. In certain local areas, where the oxide layer is thin enough, the brass layer could remelt and form a reaction layer, which in this case consists of Al-Fe-Si phases. Interestingly, no zinc and barely any copper were detected in this reaction layer, and no $\mathrm{Al}-\mathrm{Cu}$ phases had formed. While $\mathrm{Zn}$ has a relatively high solubility in $\mathrm{Al}, \mathrm{Cu}$ was expected to form the eutectic binary $\mathrm{Al}_{2} \mathrm{Cu}$ phase instead. The low concentration of $\mathrm{Cu}$ at the interface would suggest that $\mathrm{Cu}$ along with $\mathrm{Zn}$ has diffused into the cast A356 upon melting. It should also be noted that compared to the other coatings, the thickness of the reaction layer with intermetallic phases formed in the brass-coated casting is significantly thinner and that such a thickness is preferable in terms of bonding strength.

By comparing the resulting reaction layers from the various metallic coatings, it can be seen that the reaction layers appear to grow into the cast A356 alloy when galvanized and brass-coated steel inserts are used. However, for the castings with aluminized steel inserts, nearly no reaction layer has formed in the aluminum-aluminum interface, which can be attributed to the inert oxide layer on the aluminized coating surface. The characteristic tongue-like morphology of the $\mathrm{Al}_{5} \mathrm{Fe}_{2}$ phase that grow into the bulk of the steel pipe, was formed during the aluminizing process. It has previously been reported that $\mathrm{Al}_{5} \mathrm{Fe}_{2}$ is the dominating phase forming between $\mathrm{Al}$ and steel in an aluminizing process $[4,26]$. Although $\mathrm{Fe}$ atoms diffuse faster in liquid $\mathrm{Al}$ than $\mathrm{Al}$ atoms in solid $\mathrm{Fe}, \mathrm{Al}$ has a solubility of around 22 at $\%$ in iron at $600^{\circ} \mathrm{C}$ [27]. This can thus contribute to the formation of $\mathrm{Al}_{3} \mathrm{Fe}$ at the aluminum steel interface, which then leads to the formation of $\mathrm{Al}_{5} \mathrm{Fe}_{2}$ through further diffusion [4]. Addition of silicon to the aluminum alloy has been reported to act as a growth inhibitor of the reaction layer, as it promotes the formation of a more uniform $\mathrm{Al}_{3} \mathrm{Fe}$ layer that then acts as a diffusion barrier for further growth of $\mathrm{Al}_{5} \mathrm{Fe}_{2}$ [28]. Despite the silicon present in the A356 alloy, a relatively thick and irregular reaction layer is observed in the aluminized casting. This is believed to be due to a relatively long dipping time used in the aluminizing process, which then promotes further diffusion and phase growth.

For the castings with brass-coated and galvanized steel inserts, the reaction layers form upon casting. In this process, the existing metallic coating is expected to remelt, thus leaving a fresh surface for the aluminum and steel to react. However, the experimental results indicate that there is limited remelting of the brass layer and nearly no remelting of the aluminized layer. This is due to the inert aluminum oxide layers on both the aluminized insert and aluminum melt. Cheng and Wang found that an addition of $10 \mathrm{wt} \%$ Si caused mainly formation of ternary Al-Fe-Si phases and significantly reduced the fraction of binary Al-Fe phases that were observed with lower Si con- centration [29]. The A356 alloy contains 7 wt.\% silicon, which then diffuses alongside $\mathrm{Al}$ at the steel surface and then form ternary Al-Fe-Si phases as detected through the EDS analyses. In the casting process, the diffusion time is much shorter compared to the aluminizing process and therefore further diffusion of $\mathrm{Al}$ atoms into the steel and $\mathrm{Fe}$ atoms into the cast aluminum, and thus formation of thicker binary Al-Fe phases will be prevented. If also the formation of a ternary phase at the interface is preferred, it can act as a diffusion barrier for growth of the $\mathrm{Al}_{3} \mathrm{Fe}$ and $\mathrm{Al}_{5} \mathrm{Fe}_{2}$ phases, which then would cause preferred growth direction to be towards the cast A356. A thinner reaction layer is believed to have formed in the brass-coated casting compared to the galvanized casting, due to excessive Fe atoms already being present in the cast A356 for the latter.

\section{Conclusions}

The following conclusions can be made from this research:

It is possible to achieve metallurgical bonding between A356 aluminum and steel using metallic coating, such as galvanizing, aluminizing and brass-coating.

Compound casting with galvanized steel showed the most continuous metallurgical bonding, making it the best coating out of the three. Ternary Al-Fe-Si phases formed in these castings growing towards the cast A356. In addition, ternary Al-Fe-Si particles could be observed in the bulk of the cast aluminum with some distance from the reaction layer at the interface.

In the compound castings with aluminized steel, no reaction layer formed between the aluminized layer and cast A356, but local areas still showed metallurgical bonding. Instead, a reaction layer growing towards the steel pipe with the characteristic tongue-like morphology of the $\mathrm{Al}_{5} \mathrm{Fe}_{2}$ phase, formed during the aluminizing process.

The brass layer remained in most of the aluminumsteel interface in the compound castings with brass-coated steel. Only local reaction areas could form in the castings, where ternary Al-Fe-Si phases were found to grow towards the cast A356.

\section{Acknowledgements}

The authors are grateful for the financial support and contribution from the Norwegian Research Council though the IPN project "AluLean" (90141902), Aludyne Norway for material and FerroZink AS and OS ID for coating of steel pipes.

\section{References}

[1] Wang, Q. G., Metall Mater Trans A 34(12), p. 28872899 (2003)

[2] Sebaie, O. E., et al., Mater Sci Eng A 480, p. 342-355 (2008)

[3] Tayal, R. K., et al., Proc Ntl Conf Trends Advances Mechanical Engineering (2012) 
[4] Springer, H., et al., Acta Mater 59(4), p. 1586-1600 (2011)

[5] Papis, K. J. M., Loeffler, J. F., and Uggowitzer, P. J., Sci China Ser E 52(1), p. 46-51 (2009)

[6] Aylward, G., and Findlay, T., SI Chemical Data 5th ed. (John Wiley Sons Australia, Milton, 2002)

[7] Springer, H., Szczepaniak, A., and Raabe, D., Acta Mater 96, p. 203-211 (2015)

[8] Kang, M. and Kim, C. Mater Design 81, p. 95-103 (2015)

[9] Jiang, W., Fan, Z., and Li, C., J Mater Process Tech 226, p. 25-31 (2015)

[10] Jiang, W., et al., J Alloy Comp 678, p. 249-257 (2016)

[11] Jiang, W., et al., J Alloy Comp 688, p. 742-751 (2016)

[12] Smith Stål, Lagerkatalog-Smith Stål (2013)

[13] Seifeddine, S., Johansson, S., and Svensson, I. L., Mater Sci Eng A 490(1-2), p. 385-390 (2008)

[14] Springer, H., et al., Mater Sci Eng A 528, p. 46304642 (2011)

[15] Maitra, T. and Gupta, S. P., Mater Charact 49(4), p. 293-311 (2002)

[16] Sasaki, S. and Yakou, T., Surf Coat Technol 201(6), p. 2131-2139 (2006)

[17] Zheng, Y., et al., J Alloy Comp 649, p. 291-296 (2015)
[18] Tavassoli, S., Abbasi, M., and Tahavvori, R., Mater Design 108, p. 343-353 (2016)

[19] Pokorny, P., et al., Metalurgija 55(1), p. 111-114 (2016)

[20] Baker, H. and Okamoto, H., Binary Alloy Phase Diagrams, in ASM Handbook, Volume 03 - Alloy Phase Diagrams (ASM International, 1992), p. 206

[21] Su, X., Tang, N.-Y., and Toguri, J. M., J Alloy Comp 325(1-2), p. 129-136 (2001)

[22] Ma, Z., et al., Mater Sci Eng A 490(1-2), p. 36-51 (2008)

[23] Ponweiser, N., Lengauer, C. L., and Richter, K. W., Intermetallics 19(11), p. 1737-1746 (2011)

[24] Murray, J. L., B Alloy Phase Diag 4(1), p. 55-73 (1983)

[25] Qiu, P. and Leygraf, C., Appl Surf Sci 258(3), p. 1235-1241 (2011)

[26] Bahadur, A. and Mohanty, O. N., Mater Trans 32(11), p. 1053-1061 (1991)

[27] Kattner, U. and Massalski, T., Binary Alloy Phase Diagram (ASM International, Material Park, 1990)

[28] Takata, N., Manamu, N., Kobayashi, S., and Takeyama, M., Intermetallics 54, p. 136-142 (2014)

[29] Cheng, W. J. and Wang C. J., Intermetallics 19(10), p. $1455-1460(2011)$ 